de novos comportamentos físicos. Referem-se de seguida, a título de exemplo, três casos de compostos ou famílias de compostos de urânio com comportamentos físicos particularmente interessantes.

O composto $\mathrm{UFe}_{4} \mathrm{Al}_{8}$, de estrutura cristalográfica tetragonal, apresenta um comportamento ferromagnético abaixo da temperatura de $150 \mathrm{~K}$ com uma estrutura magnética complexa. A sua estrutura magnética, determinada por difracçâo de neutrões, revelou que os momentos magnéticos dos átomos de urânio e de ferro não estão alinhados paralelamente, mas sim aproximadamente perpendiculares, com os do urânio orientados ferromagneticamente segundo o eixo cristalográfico $a$ (ou b) e os de ferro ordenados quase antiferromagneticamente segundo $b$ (ou $a$ ), mas com um pequeno ângulo que os faz contribuir também para o ferromagnetismo. Um estudo pormenorizado das propriedades magnéticas, de transporte eléctrico e de espectroscopia de Mössbauer em monocristais deste composto mostrou que, em consequência das interacções magnéticas complexas, existe uma grande anisotropia magnética não só entre as direç̧ões $a$ e $c$, mas também no plano $a-b$. Esta anisotropia a baixa temperatura provoca, quando da aplicação de um campo magnético, um comportamento inédito dos domínios magnéticos que ficam bloqueados num estado metaestável intermédio, orientados perpendicularmente ao campo aplicado, geometria esta que, a priori, seria uma das menos favoráveis energeticamente. $O$ estudo das estruturas e do comportamento magnético neste tipo de compostos permite o desenvolvimento de modelos teóricos das interacções magnéticas e o avanço da compreensão de novos materiais como supermagnetes.

Outro exemplo de comportamento das propriedades físicas menos comum e relevante em estudos de matéria condensada é dado pelos sistemas ditos fermião pesado, em que os electrões de condução apresentam massas efectivas várias ordens de grandeza superior não só à dos electrões livres como mesmo à dos electrões nos sistemas metálicos habituais. Este comportamento deve-se à contribuição dos electrões $5 \mathrm{fem}$ bandas relativamente estreitas que podem dar origem a um grande pico na densidade de estados electrónicos junto ao nível de Fermi. Esta grande densidade de estados provoca um enorme aumento do coeficiente linear do calor específico, e os electrões comportam-se como se a sua massa tivesse um valor entre 10 e 100 vezes superior ao dos metais simples. Além deste tipo de comportamento, existem sistemas de fermiões pesados com ordem antiferromagnética e com fases supercondutoras a baixa temperatura, o que tem atraído imenso interesse pelo estudo destes sistemas. Dos seis sistemas de fermiões pesados que apresentam superconductividade a baixas temperaturas cinco são compostos de urânio e destes, quatro apresentam a rara coexistência entre supercondutividade e antiferromagnetismo. 0 estudo deste tipo de compostos tem produzido importantes avanços na compreensão da superconductividade e do magnetismo.

Por último, como exemplo também muito interessante, refere-se o composto intermetálico de $\mathrm{UGe}_{2}$ recentemente reportado como um ferromagnete itinerante abaixo da temperatura de $52 \mathrm{~K}$ mas que se pode transformar num superconductor, desde que seja aplicada uma pressão acima de 1.0 GPa. Embora seja um trabalho muito recente, a descoberta deste fenómeno abre enormes perspectivas para o estudo da superconditividade e da sua relação com o magnetismo

\title{
O Urânio em Fase Gasosa
}

$\mathrm{E}$ M FASE CONDENSADA, SEJa EM SOluÇão ou no estado sólido, os processos químicos são claramente influenciados pelo meio denso formado pelo solvente ou pela rede. Em fase gasosa, em particular num sistema funcionando a baixas pressões como um espectrómetro de massa, podem estudar-se as propriedades quimicas intrínsecas de espécies iónicas na ausência de factores de perturbação devidos ao meio.

No Departamento de Química do ITN temos vindo a utilizar a espectrometria de massa para estudar a reactividade em fase gasosa de iões das séries dos lantanídeos e dos actinídeos com diferentes moléculas orgânicas, examinando os mecanismos, a cinética e a energética das reacções. O objectivo tem sido tentar compreender os padrões de reactividade dos iões metálicos do bloco fatravés da sua relação com as estruturas electrónicas dos iões. Simultanea- 
mente, temos estudado a química em fase gasosa de novas espécies organometálicas daqueles elementos, procurando diferenças e semelhanças com sistemas equivalentes em fase condensada.

A técnica experimental de que dispomos, a espectrometria de massa de ressonância ciclotrónica de iões com transformada de Fourier (FT-ICR/MS) [1], emprega um campo magnético e um campo eléctrico estáticos para confinar iões numa região finita do espaço e aí os detectar. Toda a experiência de FTICR/MS ocorre numa armadilha de iões ("ion trap"), geralmente de geometria cúbica ou cilíndrica, que é mantida sob vácuo ultra-elevado no centro do campo magnético, habitualmente produzido por um magnete supercondutor. A armadilha ou célula de confinamento de iões é formada por três pares de pratos em oposição que têm funções específicas de confinamento ("trapping"), excitação e detecção dos iōes a serem analisados. A célula está colocada na zona homogénea do campo magnético de tal forma que este confina cada ião radialmente, obrigando-o a descrever um movimento de ciclotrão com uma frequência que é função da respectiva razão massa/carga $\left(\omega_{c}=q B / m\right)$, enquanto que o campo eléctrico gerado por um potencial electrostático aplicado aos pratos de "trapping" mantém o ião num fosso de potencial na direcção axial. Quando os iões presentes na célula são sujeitos a um campo eléctrico oscilante de radiofrequências transmitido através dos pratos de excitação, verifica-se ressonância com as frequências de ciclotrão dos iōes, a que corresponde uma absorção de energia que força os iões a deslocarem-se para órbitas de maior raio, aproximando-se dos pratos de detecção, nos quais induzem uma corrente imagem que é uma sobreposição das frequências de ciclotrão dos diferentes iões sujeitos a excitação, com amplitudes que são proporcionais ao número de iōes. O sinal transiente detectado é convertido numa voltagem, digitalizado e sujeito a uma transformada de Fourier, a qual revela as frequências e intensidades que são depois con- vertidas em massas e abundâncias iónicas.

Devido à sua capacidade de confinamento de iões e de realização de sequências complexas de manipulação desses mesmos iões, tais como ejecção, aceleração-excitação e colisão com espécies neutras, a técnica FT-ICR/MS é especialmente adequada para obter informação sobre a cinética, os mecanismos e a energética de reacções ião/molécula na fase gasosa.

Convém mencionar que numa reacção ião/molécula em solução, devido ao efeito da solvatação, haverá sempre uma barreira de activação inicial a ultrapassar. Em fase gasosa, na ausência de solvente, entre um ião e uma molécula neutra estabelece-se uma força atractiva a longa distância do tipo ião-dipolo induzido (a que pode acrescer uma interacção ião-dipolo permanente ou ião-quadrupolo, consoante o caso) que origina inicialmente um fosso na superfície de energia potencial. Essa energia pode ser superior a quaisquer barreiras de activação presentes e, assim, as reacçōes ião/molécula em fase gasosa podem ser até duas ordens de grandeza mais rápidas do que em solução.

Num espectrómetro de massa FT-ICR, devido às baixas pressōes de trabalho, os processos reaccionais ião/molécula são bimoleculares e sequenciais. Além disso, devido ao grande excesso de moléculas neutras relativamente aos iões, as reacções seguem cinéticas de pseudo-primeira ordem. As constantes de velocidade $k$ obtidas em estudos cinéticos são habitualmente comparadas com constantes teóricas de velocidade de colisão $k_{L}$ (Langevin) ou $k_{A D O}$ ("Average Dipole Orientation"), determinadas a partir do tipo de interacçōes presentes num dado sistema ião/molécula. Define-se assim uma eficiência de reacção $k / k_{L}$ ou $k / k_{A D O}$ que representa a fracção das colisões ião/molécula que são efectivas na formação dos produtos de reacção.

O espectrómetro de massa FT-ICR existente no Departamento de Química do ITN encontra-se em operação desde finais de 1991 e refira-se que as primei- ras experiências realizadas envolveram precisamente a produção de iōes de urânio por dessorção com laser a partir de urânio metálico e o estudo das reacçōes dos iōes formados com benzeno De então para cá, no que se refere ao urânio em fase gasosa ou, mais exactamente, à química de iões de urânio em fase gasosa, foram estudadas reacções de iōes de urânio $\left(\mathrm{U}^{+}\right.$e $\left.\mathrm{U}^{2+}\right)$ e de óxidos de urânio $\left(\mathrm{UO}^{+}\right.$e $\left.\mathrm{UO}_{2}^{+}\right)$com arenos [2], de iões de urânio $\left(U^{+}\right)$e óxidos de urânio $\left(\mathrm{UO}^{+} \mathrm{e} \cup \mathrm{O}_{2}{ }^{+}\right)$com álcoois [3], clorobenzeno [4], ferroceno e pentacarbonilo de ferro [5], e a formação do ião uranilo $\mathrm{UO}_{2}{ }^{2+}$ "nu" [6].

Este último trabalho com o ião uranilo constitui um bom exemplo do que pode ser um estudo de química de iões em fase gasosa, pondo também em evidência as potencialidades da técnica de FTICR/MS, pelo que descreveremos em seguida, sumariamente, os seus principais resultados.

$\mathrm{O}$ ião uranilo $\mathrm{UO}_{2}{ }^{2+}$ é provavelmente a espécie mais comum ao nivel da química de coordenação do urânio, tendo por isso sido amplamente estudado em solução e no estado sólido, desconhecendo-se, no entanto, ao tempo da realização deste trabalho, a existência e as propriedades termoquímicas básicas do ião isolado ou "nu", facto este que nos levou a tentar observá-lo experimentalmente em fase gasosa e a caracterizá-lo temoquimicamente. Assim, verificámos que era de facto possivel gerar no espectrómetro de massa FT-ICR a espécie $\mathrm{UO}_{2}{ }^{2+}$ isolada, por reacção com $\mathrm{O}_{2}$ ou com $\mathrm{N}_{2} \mathrm{O}$ de iões $\mathrm{U}^{2+}$ produzidos por dessorção/ionização com laser de urânio metálico. Na reacção com oxigénio observou-se a formação inicial de $\cup^{2+}$ com uma eficiência $k / k_{L}=1,0$, espécie que por sua vez reagia com uma nova molécula de $\mathrm{O}_{2}$ para dar então o ião $\mathrm{UO}_{2}{ }^{2+}$, desta vez com uma baixa eficiência $k / k_{L}=0,04$; num terceiro passo, 0 ião $\cup_{2}{ }^{2+}$ reagia por transferência electrónica com uma nova molécula de $\mathrm{O}_{2}$ para dar $\mathrm{UO}_{2}{ }^{+} \mathrm{e}_{2}{ }^{+}$, com uma eficiência $k / k_{L}=0,35$. No caso da reacção com $\mathrm{N}_{2} \mathrm{O}$, verificou-se que no primeiro passo se formavam $80 \%$ de $\mathrm{UO}^{2+}$ e $20 \%$ de $U \mathrm{~N}^{+}$com uma eficiência $k / k_{A D O}=1,0 ; 0$ 
ião $U^{2+}$ reagia então como uma nova molécula de $\mathrm{N}_{2} \mathrm{O}$ para dar o ião uranilo $\mathrm{UO}_{2}{ }^{2+}$, de novo com uma eficiência $k / k_{A D O}=1,0$, a que se seguia, tal como no caso do oxigénio, um processo de transferência electrónica para dar $\cup_{2}{ }^{+}$ e $\mathrm{N}_{2} \mathrm{O}^{+}$, desta vez com uma baixa eficiência $k / k_{A D O}=0,03$. Foi estudada também a oxidação de $\mathrm{U}^{2+} \mathrm{com} \mathrm{CO}_{2}$, mas neste caso observou-se que a reacção parava no passo inicial de formação de $\cup^{2+}\left(k / k_{L}=0,8\right)$. A partir das reacções observadas, e considerando que nas condiçōes experimentais utilizadas apenas podem ocorrer reacçōes exotérmicas ou atérmicas, foi possivel obter uma estimativa da entalpia de formação do ião uranilo $\Delta \mathrm{H}^{\circ}\left(\mathrm{UO}_{2}{ }^{2+}\right)=1552 \pm 251$ $\mathrm{kJ} / \mathrm{mol}$ e, consequentemente, da segunda energia de ionização do dióxido de urânio $2^{a} \mathrm{EI}\left({\cup \mathrm{O}_{2}}\right)=15,4 \pm 2,6 \mathrm{eV}$. Atendendo aos erros relativamente elevados destas estimativas, o estudo incluiu também cálculos teóricos que se mostraram concordantes com os valores das estimativas. A obtenção do ião uranilo isolado foi também tentada e conseguida usando um espectrómetro de massa de quatro sectores e configuração $B E B E$, usando a técnica de "chargestripping" a partir de iões $\mathrm{UO}_{2}{ }^{+}$.

O trabalho no Departamento de Química do ITN no domínio da química de iões em fase gasosa de lantanídeos, de urânio e outros actinídeos, usando a técnica FT-ICR/MS, prossegue procurando estudar sistemas, tais como "clusters" e complexos organometálicos, que se aproximem das espécies conhecidas em fases condensadas, usando novas técnicas de ionização como "electrospray" para aceder a espécies de partida menos estáveis e a estudos de especiação de actinídeos em solução, e expandindo os estudos até agora efectuados com iões simples de urânio e tório a outros elementos da série dos actinídeos, tais como protactínio, neptúnio, plutónio, amerício e cúrio.

\section{Agradecimentos}

Todo o trabalho com o urânio em fase gasosa no Departamento de Química do ITN foi ou continua a ser realizado com a participação de António Pires de
Matos, João Paulo Leal, José Manuel Carretas, Maria da Conceição Vieira e Marta Santos. Partes do trabalho foram efectuadas com a colaboração dos grupos do Prof. Helmut Schwarz da Technische Universität Berlin e do Prof. Alan G. Marshall do National High Magnetic Field Laboratory - Florida. O trabalho tem tido o apoio financeiro da JNICT/FCT e da NATO.

\section{Referências}

[1] J. Marçalo, Química (Boletim da Sociedade Portuguesa de Química) 1997, 66, 32-41

[2] J. Marçalo, J. P. Leal, A. Pires de Matos, A. G. Marshall, Organometallics 1997, 16, 4581-4588.

[3] J. M. Carretas, J. Marçalo, A. Pires de Matos, A. G. Marshall, artigo em preparação.

[4] M. Santos, J. Marçalo, A. Pires de Matos, resultados não publicados.

[5] M. C. Vieira, J. Marçalo, A. Pires de Matos, J. Organomet. Chem. 2001, no prelo.

[6] H. H. Cornehl, C. Heinemann, J. MarçaIo, A. Pires de Matos, H. Schwarz, Angew Chem. Int. Ed. Engl. 1996, 35, 891-894.

\section{Urânio (VI):}

\section{Luminescência e fotoquímica em sólidos e em solução}

A DESCOBERTA DE URÂNIO FOI ANUNCIADA em 1789 [1]. Só 16 anos depois, foi publicado o primeiro artigo sobre uma reacção fotoquímica de um composto de urânio, a transformação do sulfato ou nitrato de uranilo, na presença de etanol, a uma outra forma [2]. Hoje, sabemos que a reacção envolve a fotooxidação do etanol para formar acetaldeído, com formação de urânio U(IV). Em solução na presença do ar, o urânio(VI) é o estado de oxidação mais estável, e a forma mais comum é o ião uranilo $\left(\mathrm{UO}_{2}{ }^{2+}\right)$. Esta espécie tinha um papel importante no desenvolvimento das ideias sobre espectroscopia e a dispersão de luz no século XIX, e como indicado na introdução tais investigações pela família Becquer el resultaram na descoberta da radioactividade em 1896. Mais pormenores desses estudos são discutidos na introdução e num outro artigo [3]. A aplicação mais importante de urânio nesta altura era na coloração de vidro [4]. É o urânio(VI) que é o estado de oxidação mais importante. A fotoquímica do ião uranilo também teve um papel importante no projecto Manhatt$\tan$ na separação de ${ }^{235} \cup$ para efeitos nucleares $[3,5]$

Nesta comunicação focámos algumas áreas de estudo,como a luminescência e a fotoquímica de urânio(VI), realizadas pelo grupo de Coimbra nos últimos 28 anos. Começámos com uma discussão das propriedades fotofísicas em geral. 